\title{
Building stock simulation to support the development of a district multi-energy grid
}

\author{
Francesco Causone $^{1^{*}}$, and Martina Pelle ${ }^{1}$ \\ ${ }^{1}$ Politecnico di Milano, Department of Energy, via Lambruschini 4, 20156 Milano, Italy
}

\begin{abstract}
The urbanization process is constantly increasing worldwide. Today over $50 \%$ of the population resides in urban areas and this value is expected to grow up to $68 \%$ by 2050 . In this scenario, the development of district scale energy grids and management systems has become crucial to optimize energy use and to balance energy flows within the cities, encouraging the use of renewable sources and selfconsumption. This study focusses on a district under development in the city of Milan, involving an urban area of about $920000 \mathrm{~m}^{2}$, which, once completed, will count for about 4500 apartments, a school and a few other commercial uses. The existing energy systems consist of an electric grid, including a small photovoltaic field, a district heating system and a local district cooling system exploiting groundwater via heat pumps. They serve, at present, seven residential tower buildings (400 apartments). The overarching aim of the research is to evolve the existing grid into a smart energy grid able to guarantee an intelligent management of the district, empowering eventually people to apply for demand-response schemes, electric mobility and other innovative services. In order to perform such an improvement and extension of the exiting grid, it is necessary to evaluate and simulate the profiles and dynamics of the final energy uses for the residential buildings, that will represent the major load on site. Since monitoring data are not yet available for the district, the evaluation of the energy performance of the existing buildings has been developed through dynamic energy simulations via the definition of profile loads of the most frequent apartment typologies, that allow, moreover, to simulate further developments in the districts. Besides, a monitoring plan for the existing systems has been developed and implemented. Monitoring data will be used at first for validating the developed load profiles; then, they will be analysed to develop optimisation algorithms for the management of the upgraded energy grid. In this paper, the case study is presented and the results of the analysis, via energy simulation, on the existing building stock are reported.
\end{abstract}

\section{Introduction}

In the last decades, politic and economical efforts have been undertaken in order to achieve the reduction of $\mathrm{CO}_{2}$ emissions established in the international agreements [12]. One of the most challenging commitment required for decarbonisation, is the improvement of energy efficiency in buildings [3]. Indeed, it has been calculated that one third of the overall energy consumptions in the industrialized countries is related to buildings [4-5] and, in large part, this energy is used by heating and cooling systems to provide comfortable indoor environments for the occupants [5-6]. A large part of the global emissions are imputable to cities, which consume about $75 \%$ of total primary energy and emit between $50 \%$ and $60 \%$ of the world's total greenhouse gases [7]. Moreover, $55 \%$ of the world's population currently lives in urban areas and projections show that the urbanization process is growing; thus, the share of urban population is expected to increase to $68 \%$ by 2050 [8]. The energy demand and the emissions of cities are expected to grow further, and it will be very challenging to meet the needs of the rising urban population reducing emissions. Urban energy management is becoming, therefore, a crucial element for the sustainable development of urban areas [8-10]. In particular, district scale energy grids and management systems has become decisive to optimize energy uses and to balance energy flows within the cities, integrating renewable systems, storage systems and implementing, when possible, demand response programs [11]. The smart management of distributed energy resources and their interaction with microgrids and buildings has become a pivotal research area toward the transition from smart grids related to electricity only, which are a singlesector systems, to a holistic and integrated design of future sustainable multi-energy systems, which involve multiple forms of energy (electricity, gas and heat) $[10,11]$. The main design aspects for such systems rely on the daily scheduling of the production plants, the reliable modelling of daily energy use of buildings (at increasing temporal and spatial resolution) and the correct evaluation of operational management aspects $[9,12]$. The implementation and design of smart energy systems in existing urban contexts is a challenging task, mainly when it comes to the assessment of the energy demand of cities or neighbourhoods, for which detailed physical models are too complex and time consuming to be implemented [13-16]. At large scale (cities, regions, nations) statistical

\footnotetext{
${ }^{*}$ Corresponding author: francesco.causone@polimi.it
} 
"top-down" or physical (simplified) "bottom-up" approaches have been used during the last years. Among these, Urban Building Energy Models (UBEM) turned out to be the most versatile, allowing for the integration of geometric characteristics and no-geometric ones, (such as construction techniques, usage, internal loads) which make them suitable for the analysis of the existing stock and for the development of future scenarios $[13,15,16]$.

This study is meant to analyse and optimize the performance of a district multi-energy grid in Milan, consisting in an electric grid (including a small photovoltaic field), a district heating system and a local district cooling system exploiting groundwater via heat pumps. The overarching aim is to evolve the existing grid into a smart multi-energy grid, able to guarantee an intelligent management of the district in order to reduce the primary energy consumptions. To do so, it is necessary to simulate and evaluate the dynamic profiles of the energy uses of the existing buildings and to predict the energy uses due to the further development of the district. Thus, a dynamic energy model of the existing buildings has been developed and energy needs identified. The data will serve as baseline for the identification of different scenarios for the future development of the district. In a second step, the results will be validated via measured data, which will be collected by means of a monitoring plan that has been developed. Furthermore, the monitoring plan is meant to assess the status of the energy supply systems to develop optimization algorithms for the management of the upgraded energy grid. This paper describes the case study, the energy modelling strategy and presents the result of the analysis on the existing building stock for the identification of energy loads.

\section{Project description}

\subsection{Buildings}

This study focuses on a district under development in Milan that involves a large urban surface of $920000 \mathrm{~m}^{2}$ and that, once completed, will include a large residential area of 4500 apartments, a school and a few other commercial uses. The residential area is divided in 11 parcels, each one including several buildings. The study is focused on parcel R09/3, which consists of nine tower buildings; seven completed and two under construction (Fig. 1: Buildings 3 (B3) and 4 (B4) do not exist yet). The buildings have different heights, volumes and envelope technologies, and count for an aggregate volume of $111000 \mathrm{~m}^{3}$ and about 400 apartments of different size and typology, as shown in Table 1 . The main geometrical characteristics of the buildings are summarized in Table 3. Building 1 (B1), made of 23 stories, is the highest, whereas Building 7 (B7), 11 stories high, is the smallest. The envelope technologies are summarized in Table 2.

\subsection{District energy systems}

The energy generation systems on the analysed parcel consist of a district heating system for space heating and domestic hot water (DHW), a local district cooling system exploiting groundwater via heat pumps for space cooling and an electric grid, which includes a small photovoltaic field. The district heating has independent circuits for each building, all connected to a delivery point in the parcel, for both space heating and domestic hot water (DHW) with a delivery temperature of $110{ }^{\circ} \mathrm{C}$. The heating distribution circuits supply a low temperature fluid to radiant floor heating systems in each apartment [19 - 20], while the DHW circuits consist in a series of water tanks and pumps which supply hot water at constant temperature. The district cooling system has a unique circuit for the entire district, with thirteen extraction wells and fourteen re-injection wells that are distributed throughout the district and which serve an interconnected circuit that consists of three loops spread on the district and of a single loop (loop 4) which serves the Eastern parcels of the district (Fig. 2). Each parcel is linked to the circuit and uses a thermal storage to exploits groundwater via independent heat pumps. The analysed parcel has two heat pumps to cover the thermal load for cooling in the warmer periods, plus two heat exchangers for free cooling during the mid-seasons. No demand-side storage is present in the heating and cooling circuits, which directly serves radiant floor systems in each apartment. A centralized controlled mechanical ventilation (CMV) unit, with heat recovery, is installed on each building and provides outdoor primary air required for the apartments. Furthermore, each apartment is equipped with individual small dehumidification batteries. A small photovoltaic field with a total pick power of $39.3 \mathrm{kWp}$ is installed on the roof of the seven buildings. It has two-way electric meters, which allow the self-consumption of the produced energy for the common electric uses when needed and the transfer of the extra production to the national grid.

Table 1. Number of apartments per typology and buildings.

\begin{tabular}{lcccccc}
\hline & $\begin{array}{c}\text { One } \\
\text { room }\end{array}$ & $\begin{array}{c}\text { Two } \\
\text { rooms }\end{array}$ & $\begin{array}{c}\text { Three } \\
\text { rooms }\end{array}$ & $\begin{array}{c}\text { Four } \\
\text { rooms }\end{array}$ & $\begin{array}{c}\text { Five } \\
\text { rooms }\end{array}$ & Tot \\
\hline B1 & 0 & 16 & 49 & 17 & 1 & 83 \\
B2 & 0 & 13 & 31 & 12 & 1 & 57 \\
B5 & 0 & 14 & 45 & 10 & 0 & 69 \\
B7 & 1 & 3 & 35 & 0 & 0 & 38 \\
B9 & 0 & 10 & 18 & 10 & 0 & 38 \\
B10 & 0 & 1 & 54 & 0 & 0 & 55 \\
B11 & 0 & 7 & 42 & 7 & 0 & 56 \\
Tot & 1 & 64 & 274 & 56 & 2 & 396 \\
\hline
\end{tabular}

Table 2. Thermal transmittances of envelope technologies $\left[\mathrm{W} /\left(\mathrm{m}^{2} \mathrm{~K}\right)\right]$. M1: external wall; $\mathrm{M} 2$ : external wall adjacent to concrete structure; M5: internal wall between apartments; M6: internal wall adjacent to unheated spaces; P1: floor between apartments; P2: floor slab between apartments and unheated spaces; S4: roof.

\begin{tabular}{cccccc}
\hline ID & B1 & B2 - B7 & B9 - B10 & B11 & B5 \\
\hline M1 & 0.175 & 0.161 & 0.161 & 0.161 & 0.161 \\
M2 & 0.219 & 0.219 & 0.219 & 0.219 & 0.219 \\
M5 & 0.236 & 0.236 & 0.236 & 0.236 & 0.236 \\
M6 & 0.341 & 0.341 & 0.341 & 0.341 & 0.341 \\
P1 & 0.490 & 0.490 & 0.490 & 0.490 & 0.490 \\
P2 & 0.266 & 0.266 & 0.147 & 0.287 & 0.136 \\
S4 & 0.204 & 0.204 & 0.180 & 0.180 & 0.180 \\
\hline
\end{tabular}


Table 3. Geometrical characteristics of the buildings on parcel R09/3.

\begin{tabular}{ccccccccc}
\hline & $\begin{array}{c}\mathbf{V}_{\text {gross }} \\
{\left[\mathbf{m}^{\mathbf{3}}\right]}\end{array}$ & $\begin{array}{c}\mathbf{V}_{\text {net }} \\
{\left[\mathbf{m}^{\mathbf{3}}\right]}\end{array}$ & $\begin{array}{c}\text { SEXT,gross } \\
{\left[\mathbf{m}^{2}\right]}\end{array}$ & $\begin{array}{c}\mathbf{S}_{\text {useful }} \\
{\left[\mathbf{m}^{2}\right]}\end{array}$ & $\begin{array}{c}\mathbf{S} / \mathbf{V} \\
{[-]}\end{array}$ & $\begin{array}{c}\mathbf{A w}_{\mathbf{w}} \\
{\left[\mathbf{m}^{2}\right]}\end{array}$ & $\begin{array}{c}\mathbf{W W R} \\
{\left[\mathbf{m}^{2}\right]}\end{array}$ & $\begin{array}{c}\mathbf{N}^{\circ} \mathbf{o f} \\
\mathbf{f l o o r s}\end{array}$ \\
\hline B1 & 23281 & 16533 & 6361 & 6123 & $27 \%$ & 1187 & $19 \%$ & 23 \\
B2 & 16552 & 11088 & 6594 & 4106 & $40 \%$ & 831 & $13 \%$ & 18 \\
B5 & 19194 & 12524 & 6832 & 4638 & $36 \%$ & 1015 & $15 \%$ & 17 \\
B7 & 11350 & 7572 & 5536 & 2805 & $49 \%$ & 613 & $11 \%$ & 11 \\
B9 & 10564 & 7096 & 4596 & 2628 & $44 \%$ & 508 & $11 \%$ & 14 \\
B10 & 17246 & 12875 & 7700 & 4768 & $45 \%$ & 1018 & $13 \%$ & 17 \\
B11 & 13118 & 8995 & 5223 & 3331 & $40 \%$ & 1136 & $22 \%$ & 17 \\
\hline
\end{tabular}
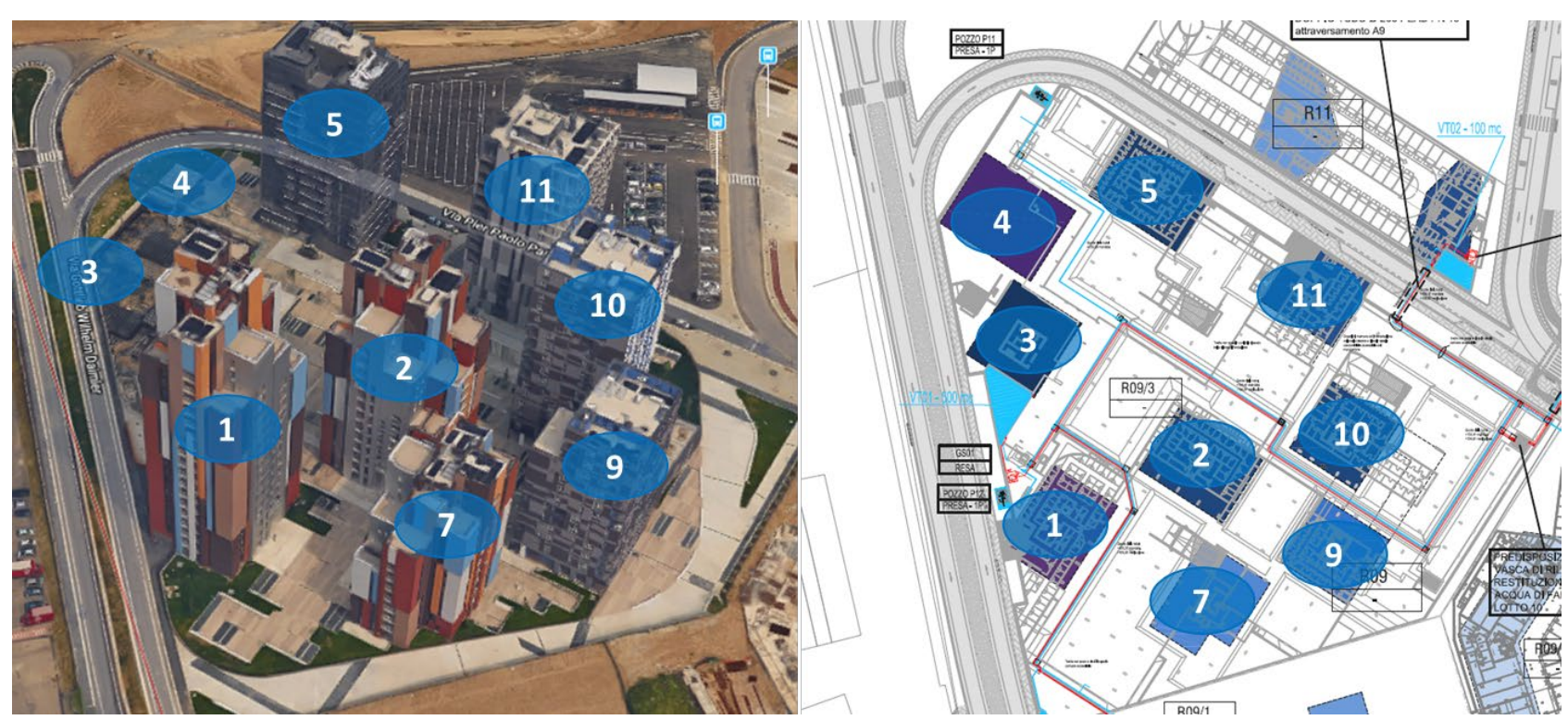

Fig. 1. Layout of the buildings on Parcel R09/3.

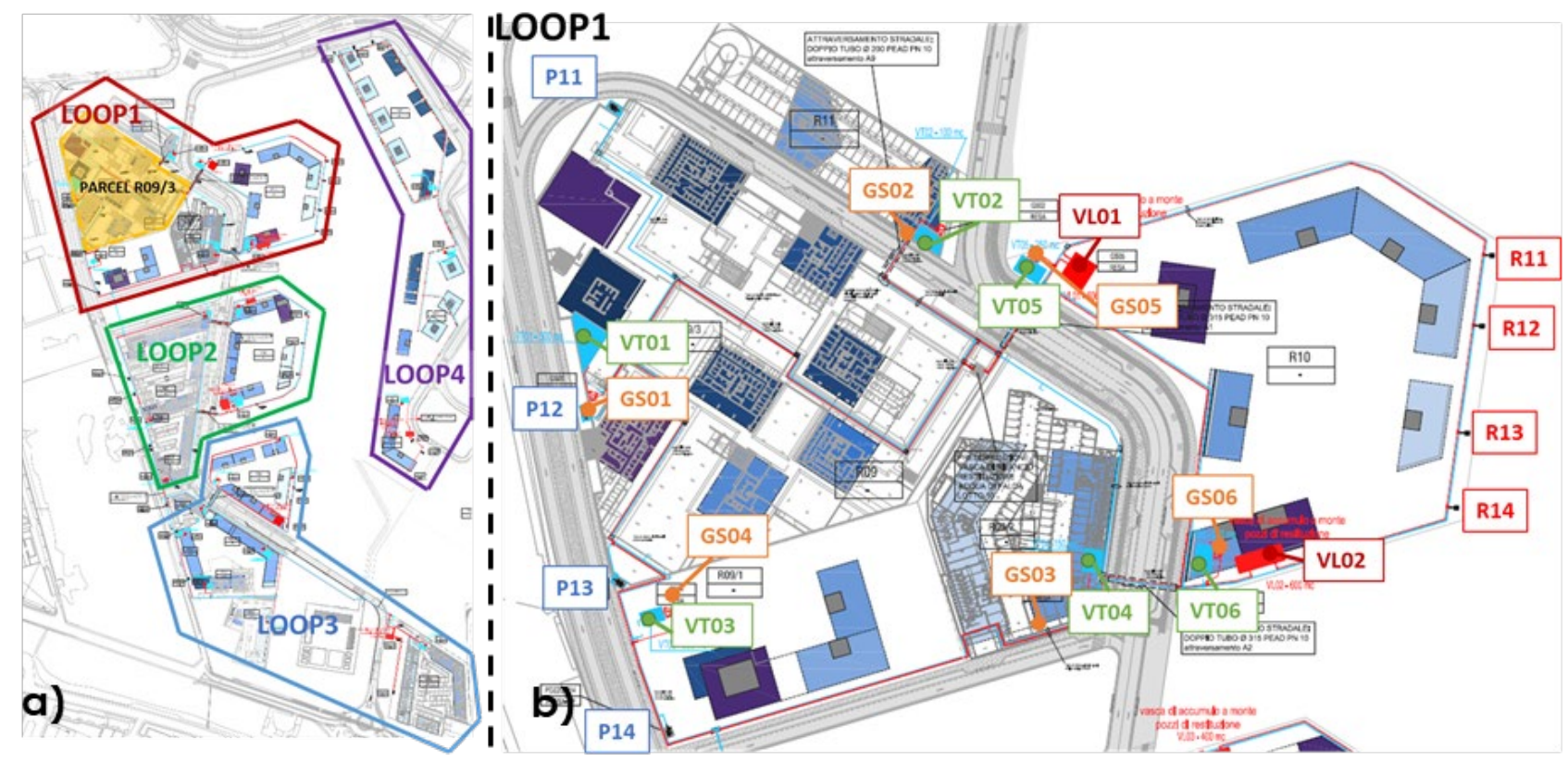

Fig. 2. Local district cooling system: a) loops identification; b) extraction wells (P11 to P14), re-injection wells (R11 to R14), thermal storage (VT01 to VT06) and outflow units (GS01 to GS06) of the first loop, serving the analysed parcel R09/3. 


\subsection{Monitoring and Management plan}

A detailed monitoring and management plan has been prepared for the whole parcel, both to identify the current status of the energy systems and to evolve them into a smart multi-carrier energy grid. Currently the three systems, i.e. cooling, heating and electric grid, are operated separately and mostly with static control (e.g. fixed set-point).

The monitoring plan includes about 600 points of measure and each one may include several metered parameters. It has been developed identifying three levels of detail: (i) the parcel, (ii) the building, (iii) the apartment, and additional levels may focus on intermediate points between the three major ones (e.g. the different manifolds within a building, serving different story clusters).

Once deployed, the monitoring plan will allow to follow in real time: (i) the delivered energy at the different levels of measure, (ii) the alarm status, (iii) the efficiency of the systems and possible losses. Since the plan will be implemented via an ICT system enabled by cloud computing, it will become also an energy management system (EMS), able to provide system optimisation and control at the parcel level. The buildings are already provided with local management systems (BMS), that the new EMS will put in contact and try to coordinate. Local control will continue to be made by BMS, but the EMS will allow to identify uneven management between buildings and inform the energy manager to balance it.

\section{Model}

\subsection{Physical model}

In order to develop the existing energy grid into a smart grid able to guarantee an intelligent management of the district, it is crucial to understand the current energy use and to simulate the district future energy scenarios. To do so, a dynamic energy model has been realised. It is meant to characterize the energy needs and uses starting from the energy analysis at the apartment level, evaluating the most frequent apartment typologies (two, three and four-rooms apartments (see Table 1)). One reference floor has been chosen, based on the average floor surface; it includes the three apartment typologies of interest. The reference floor has been simulated at three different heights: first floor (i.e. the lowest residential floor), intermediate floor, top floor, for all the seven existing buildings (Fig. 3). Each model presents the envelope technologies of the associated building (see Table 2). The boundary condition of the ceiling in the lower apartments (first floor) has been set as adiabatic, since they are adjacent to the upper apartments with similar internal setpoint conditions; whereas the floor slab, faces an unheated lower spaces (ground floor including the entrance hall). The intermediate apartments have adiabatic conditions for both the ceiling and the floor. The top apartments have adiabatic conditions for the floor, adjacent to apartments with similar internal set-point conditions, and the roof

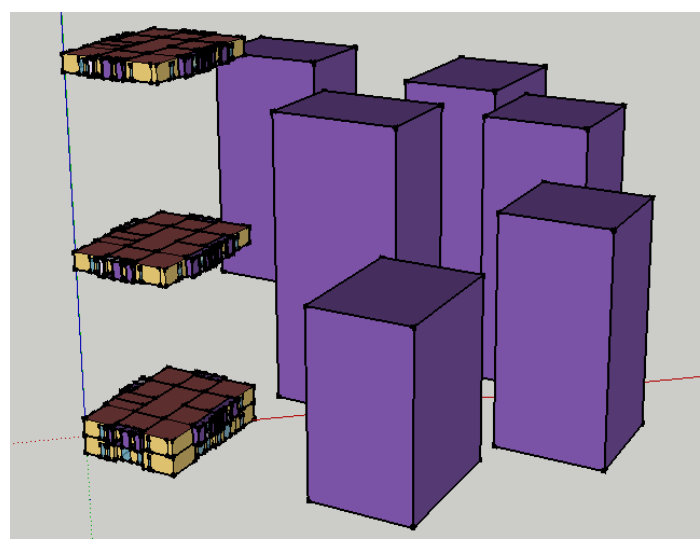

Fig. 3. Physical model of Building 1.

facing the external environment. Each building has been simulated at its actual position in the parcel, considering the effects of the other buildings' drop shadows.

\subsection{Occupant behaviour}

The modelling of occupant behaviour in building simulations is a complex task. It has been proved that occupants' behaviour has a key role in the energy use of buildings [17-20], especially when it comes to the energy use of high-efficiency buildings (low or nearly zero energy buildings [25-27]), whose variation is highly affected by the passive or active presence of people [17, 21]. Indeed, building and cities do not use energy, but people do, and to oversimplify or ignore the human factor in building simulations could lead to a mismatch between predicted and real energy use [22], called "performance gap" [29]. In this work, we decided not to use deterministic scheduled profiles of occupation and internal heat gains, but to simulate, during the year, the occupancy and the occupant-related electric energy used by appliances through stochastic schedules, which have been created using a data-driven procedure, developed by Causone et al. [30]. The schedules have been set up starting from metered data of a residential building located in Milan, using machine learning techniques. The procedure results in the identification of five clusters for the occupancy and five clusters for the electric energy used by appliances (Fig. 4). A cluster consists in a daily hourly profile of the probability of occurrence of defined energy uses or occupancy. The five clusters have been then randomly combined to build up fifteen different yearly hourly schedules, one for each apartment modelled in a building. The probability profiles have been multiplied for a defined value, derived from the same database used for the profiles generation, representing the average value for electric energy use and the number of people for each apartment typology. These values are shown in Table 4 . Both the average value of the electricity uses and the probability profiles have been derived from the metered dataset of the building analysed by Causone et al. [30], which is a residential building similar to the ones hereby studied. Both buildings are residential and located in a suburban area of Milan. Moreover, the buildings have similar apartment typologies. 


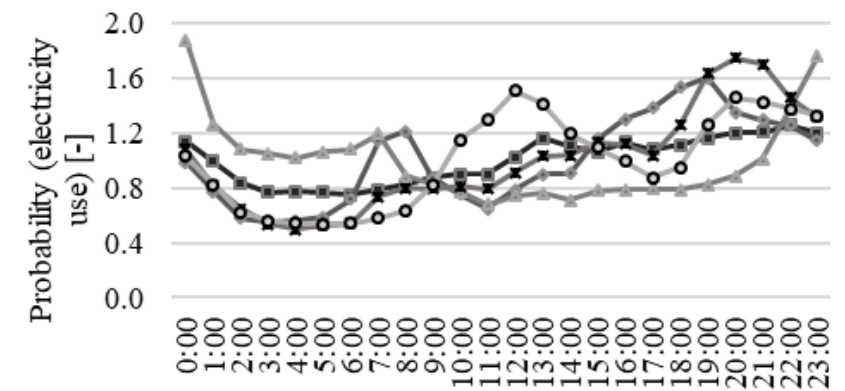

Hour of the day

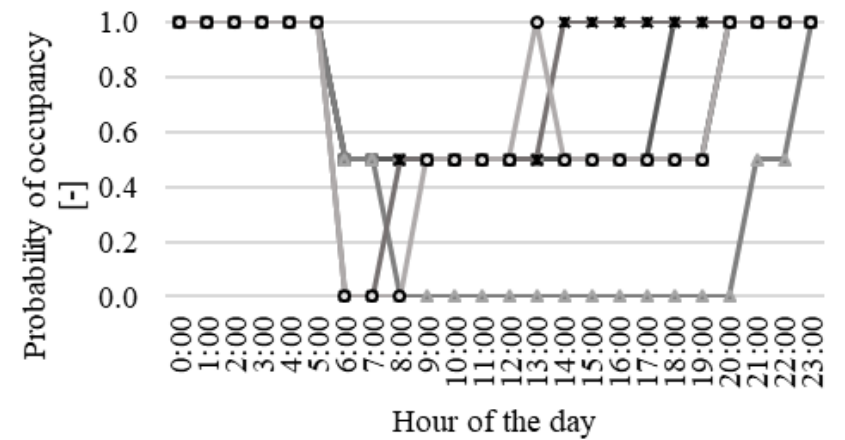

Hour of the day

$\rightarrow-$ Cluster $1 \rightarrow$-Cluster $2-$-Cluster $3 *$ Cluster $4-$-Cluster 5

Fig. 4. On the left: the five clusters of daily probability of occurrence for the appliances' and lights' electric energy use. On the right: the five clusters of daily probability of occurrence for the occupancy.

Table 4. Maximum mean value of electric energy uses and number of people for apartment typology.

\begin{tabular}{ccc}
\hline Apartment typology & Wh & People \\
\hline Two room & 165.5 & 2 \\
Three room & 198.1 & 3 \\
Four room & 202.5 & 5 \\
\hline
\end{tabular}

\subsection{Weather dataset}

In order to take in consideration local climate warming experienced in Milan in the last years, simulations have been run using a weather file developed by the Joint Research Centre (JRC) and based on data monitored from 2006 to 2015 [31]. The solar radiation data used in this weather file have been calculated from satellite data thanks to the Satellite Application Facility on Climate Monitoring (CM SAF) collaboration. All other data have been taken from the European Centre for Medium-Range Weather Forecasts (ECMWF) ERA-interim, a global atmospheric reanalysis from 1979, continuously updated in real time. Dry-bulb temperature data have been corrected for elevation. The selection of the months for the typical year is done using the method described in the international Standard ISO 15927-4 [32]. The selection is done based on dry-bulb temperature, global horizontal radiation and relative humidity.

\section{Results}

The analysis aims to define the representative load profiles for each apartment typology to be used for the characterization of current energy uses which, furthermore, will serve as baseline for the analysis of potential future developments of the district. The load profiles of all the simulated apartments in the different buildings, have been combined and mediated in order to define the representative load of each apartment typology. A weighted average has been performed: as a matter of fact, the intermediate height apartments have a higher influence on the total load of the buildings, since this typology accounts for $88 \%$ of the total, whereas first floor and top floor apartments account for $6 \%$ each.

The choice to analyse the energy at apartment level has a twofold advantage: on the one hand, it enables the management of the energy analysis with simpler models, substantially reducing the time required for its development; on the other, the profile load of a reference apartment is a versatile instrument for the deployment of different scenarios for the future extension of the district. The district developer, by combining the data that will be gathered by the management and monitoring system, and the simulation output, will be able to set requirements for architects and engineers, on how to design and built the new buildings, form their very basic units, i.e. the apartments. Moreover, operational performance might be referred, in future, to the apartment, enabling users' involvement and demand-response programs.

\section{Discussion}

The study allowed to derive the energy need profiles for heating and cooling and the energy use profile for appliances of the three analysed apartment typologies and, consequently, of the entire parcel R09/3.

Fig. 5 shows the annual hourly trend of total energy needs for heating and cooling, and of the energy use of electric appliances for the parcel R09/3. It includes also the representative annual hourly trend of the energy needs per square meter for heating and cooling, and of the energy use per square meter of electric appliances for each apartment typology. Fig. 6 (a) shows the annual energy needs per square meter for heating and cooling and total annual energy use per square meter for appliances and lights, for each apartment typology and for the parcel R09/3. The heating energy needs per square meter are quite constant for the three apartment typologies while the cooling energy needs rise as the apartment dimensions increase. The annual energy use per square meter for appliances and lights, instead, decrease slightly form the smallest to the largest apartment typology.

Fig. (b) shows the total annual energy needs and electric use for 65 two-rooms apartments, 274 three-rooms apartments and 57 four-rooms apartments (see Table 1) and the total values for parcel R09/3. Energy needs are mostly related to cooling, whereas the heating needs are significantly lower. The highest contribution in the total energy needs is given by the three-rooms apartments, since they represent the most frequent typology in the parcel. 

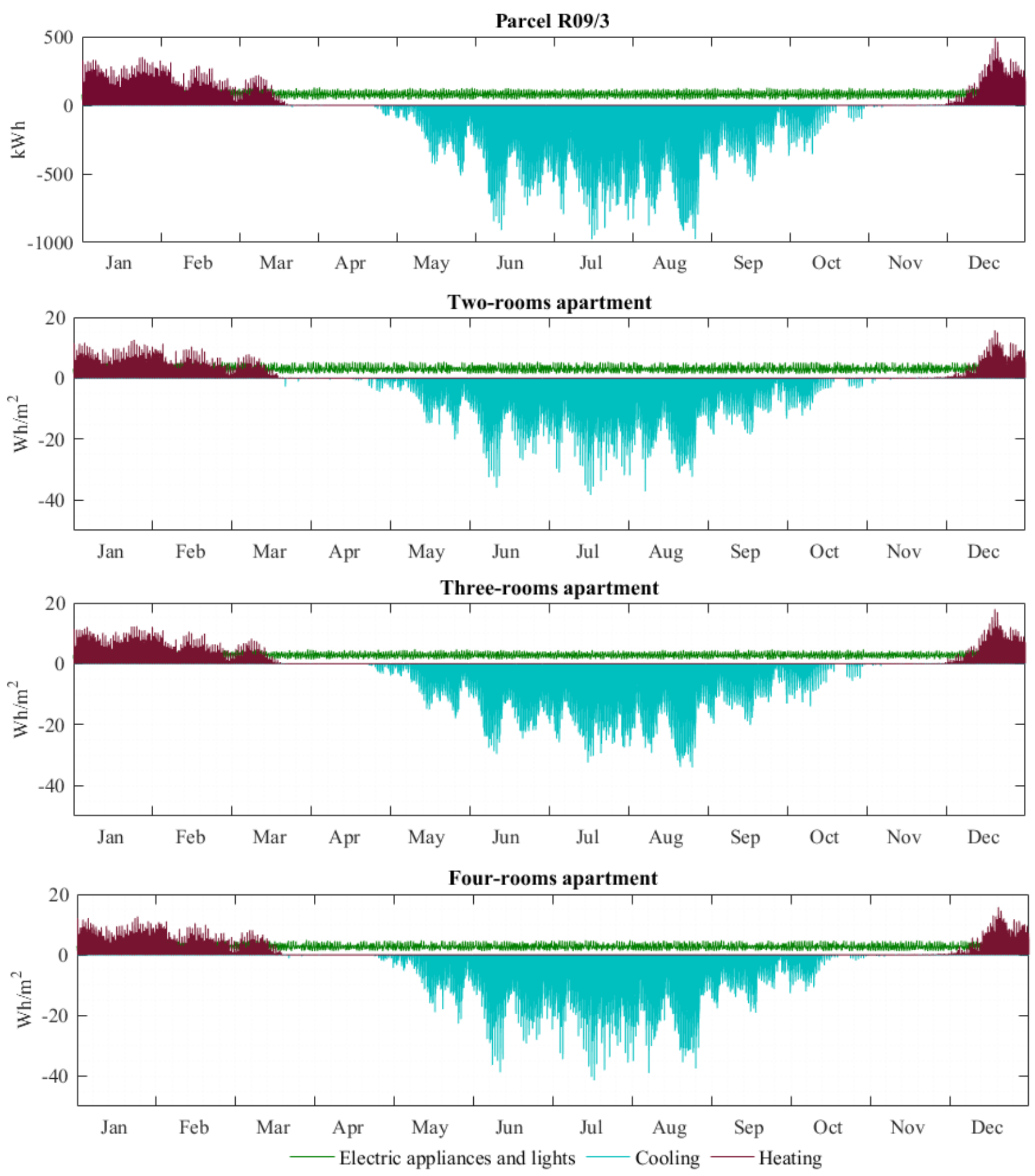

Fig. 5. Annual hourly energy needs for space heating and cooling and annual hourly electric energy uses by appliances and lights for the parcel and the three apartment typologies. From the top: parcel R09/3, three-rooms, two-rooms and four-rooms apartment.

The cooling need shows both the highest values and the most uneven profile. Vice versa, the electric energy use for appliances shows a quite stable profile, with daily and hourly fluctuations but little seasonal ones. The heating need reports quite lower pick values, with respect to the cooling need, and a lower range of variation. These results reflect some relevant boundary conditions, i.e. (i) the opaque building envelope has very good thermal performance, (ii) the transparent building envelope is not provided with solar shading, (iii) simulations have been run with a weather file built on years 2006-2015, thus incorporating the effects of local climate warming, (iv) occupant behaviour plays a pivotal role on energy use it has been considered for electrical appliances on the basis of monitored data in a similar building, but it has not been modelled for the control of heating and cooling systems (because of lack of data), that may be controlled via local thermostats.

Real data are now expected both to validate (and calibrate if necessary) the model and to transform the energy needs from simulation into energy uses at different levels. 
In particular, the simulation results will be contrasted with the energy delivered at: (i) the parcel, (ii) the building, (iii) the apartment, and (iv) other relevant sublevels (e.g. manifolds). At first instance, monitoring data will be used to evaluate the actual services systems efficiencies, necessary to transform energy needs into uses, and eventually simulation results will be compared to the metered delivered energy. From simulations is, nevertheless, already evident that the cooling system is the most stressed during the year.

This system is also the most complex and prone to issues, due to the many mechanical components. The major effects of the intelligence deployed via the new management and monitoring system will be therefore experienced here.

It is worth to point out that the warmer periods are the most critical in terms of energy needs but also the most suitable for the energy uses optimization due to the catachrestic of the cooling energy supply system. In fact, the energy for cooling is generated exploiting ground water via two heat pumps during warmer periods, and two heat exchangers for free cooling during the midseasons. Since the cooling energy need profile is highly uneven, the electric pick power required during warmer period is very irregular and it may result in very low efficiency of the generation system. Using the heat exchangers in parallel with the heat pumps, also during warmer periods, might increase the overall efficiency of the system.

\section{Conclusions}

As claimed before, the main design aspects for a smart energy system are (i) the daily scheduling of the production plants, (ii) the reliable modelling of daily energy demand of buildings at increasing temporal and spatial resolution and (iii) the correct evaluation of operational management aspects $[9,12]$.

The presented study provided a methodology for the generation of the hourly energy demand of an entire district at high spatial resolution with a simplified model, based on the simulation of representative apartment typologies. It is thus representative of the condition in which the designer is not provided with useful monitoring data. Determining the annual hourly energy need profiles of representative apartment typologies has a twofold purpose: on the one hand, it allows an easier calculation of the total energy needs of the parcel to be used for the optimization of the existing energy systems. On the other hand, it will be useful for the analysis of different future scenarios for the district development.

The early outcome of the monitoring system, deployed following a detailed monitoring plan, is shortly expected and it will allow to validate the results of the simulations and to produce the mentioned development scenarios. Besides, this it will be useful for (i) optimizing existing systems performance (especially the cooling system and the photovoltaic plant), (ii) developing optimisation algorithms for improving the management of the upgraded energy grid.

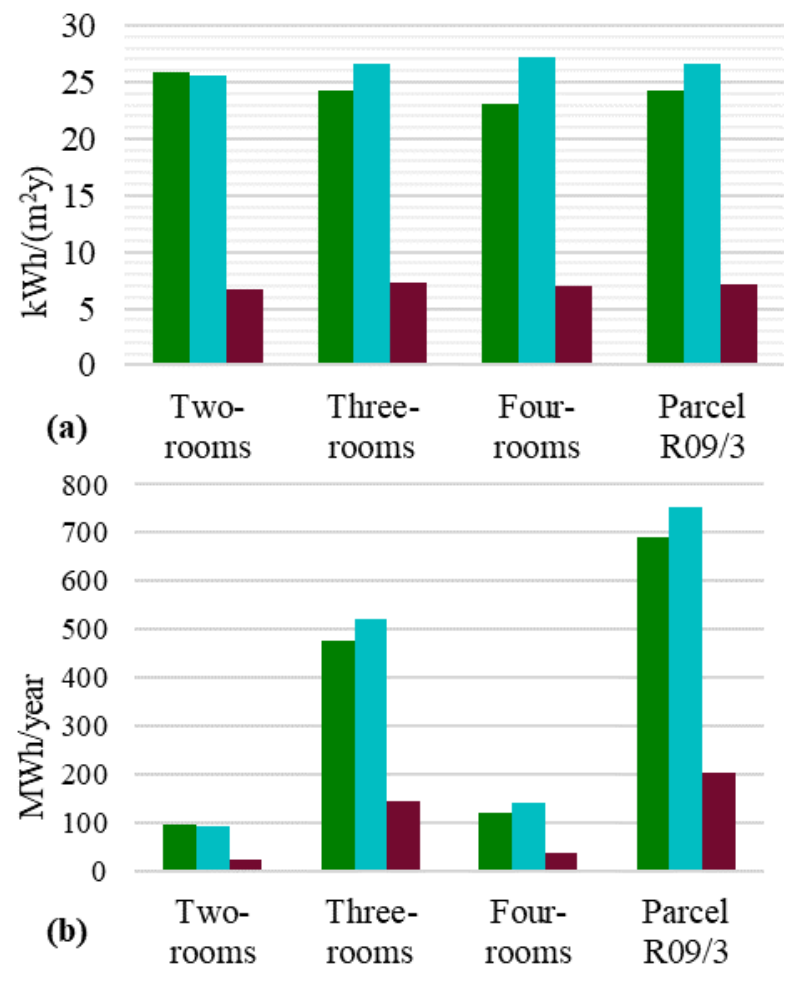

Electric appliances and lights Cooling ${ }_{\text {Heating }}$

Fig. 6. (a) Annual energy needs per square meter for heating and cooling and total annual energy use per square meter for appliances and lights of each apartment typology and the parcel. (b) Total annual energy needs for heating and cooling and total annual energy use for appliances and lights of the apartments and the parcel.

\section{Acknowledgement}

The study was partially developed within the framework of the project Sustainable Lifestyle: Merlata Smart Grid, funded by Regione Lombardia.

\section{References}

[1] United Nations Framework Convention on Climate Change Secretariat, "Kyoto Protocol," Kyoto, (1997).

[2] United Nation Framework Convention on Climate Change in 21st Conference of the Parties, "Paris Agreement," Paris, (2015).

[3] European Commission, Energy efficient buildings - Multi-annual roadmap for the contractual PPP under Horizon 2020. Publications Office of the European Union, Luxembourg, (2013).

[4] U.S. Energy Information Administration, "Commercial Buildings Energy Consumption Survey: Energy Usage Summary," (2016).

[5] U.S. Energy Information Administration, Buildings Sector Energy Consumption. U.S. Department of Energy, Washington, (2016).

[6] F. Yousefi, Y. Gholipour, and W. Yan, "A study of the impact of occupant behaviors on energy 
performance of building envelopes using occupants' data," Energy Build., vol. 148, pp. 182-198, (2017).

[7] UN-Habitat, "Urban themes: Energy." [Online]. Available: $\quad$ https://unhabitat.org/urbanthemes/energy/. [Accessed: 22-Oct-2018].

[8] United Nations Department of Economic and Social Affairs Population Division, "World Urbanization Prospects: The 2018 Revision, Online Edition”, (2018).

[9] F. Causone, A. Sangalli, L. Pagliano, and S. Carlucci, "Assessing energy performance of smart cities," Build. Serv. Eng. Res. Technol., vol. 39, no. 1, pp. 99-116, (2018).

[10] F. Causone, A. Sangalli, L. Pagliano, and S. Carlucci, "An Exergy Analysis for Milano Smart City," Energy Procedia, vol. 111, no. September 2016, pp. 867-876, (2017).

[11] J. Sokol, C. Cerezo Davila, and C. F. Reinhart, "Validation of a Bayesian-based method for defining residential archetypes in urban building energy models," Energy Build., vol. 134, pp. 1124, (2017).

[12] H. Lund, P. A. Østergaard, D. Connolly, and B. V. Mathiesen, "Smart energy and smart energy systems," Energy, vol. 137, pp. 556-565, (2017).

[13] N. Good, E. A. Martínez Ceseña, and P. Mancarella, "Ten questions concerning smart districts," Build. Environ., vol. 118, pp. 362376, (2017).

[14] S. Bracco, F. Delfino, G. Ferro, L. Pagnini, M. Robba, and M. Rossi, "Energy planning of sustainable districts: Towards the exploitation of small size intermittent renewables in urban areas," Appl. Energy, vol. 228, no. July, pp. 2288-2297, (2018).

[15] R. Aghamolaei, M. H. Shamsi, M. Tahsildoost, and J. O'Donnell, "Review of district-scale energy performance analysis: Outlooks towards holistic urban frameworks," Sustain. Cities Soc., vol. 41, no. March, pp. 252-264, (2018).

[16] P. Caputo, G. Costa, and S. Ferrari, "A supporting method for defining energy strategies in the building sector at urban scale," Energy Policy, vol. 55, pp. 261-270, (2013).

[17] W. Li et al., "Modeling urban building energy use: A review of modeling approaches and procedures," Energy, vol. 141, no. December, pp. 2445-2457, (2017).

[18] C. F. Reinhart and C. Cerezo Davila, "Urban building energy modeling - A review of a nascent field," Build. Environ., vol. 97, pp. 196-202, (2016).

[19] E. Fabrizio, S. P. Corgnati, F. Causone, and M. Filippi, "Numerical comparison between energy and comfort performances of radiant heating and cooling systems versus air systems," $H V A C R$ Res., vol. 18, no. 4, pp. 692-708, (2012).

[20] F. Causone, B. W. Olesen, and S. P. Corgnati, "Floor heating with displacement ventilation: An experimental and numerical analysis," $H V A C R$ Res., vol. 16, no. 2, pp. 139-160, (2010).

[21] O. Guerra Santin, L. Itard, and H. Visscher, "The effect of occupancy and building characteristics on energy use for space and water heating in Dutch residential stock," Energy Build., vol. 41, no. 11, pp. 1223-1232, (2009).

[22] V. Fabi, V. M. Barthelmes, Y. Heo, and S. P. Corgnati, "Monitoring and stimulating energy behavioural change in university buildings towards post carbon cities" IBPSA Build. Simul. 2017, pp. 423-429, 2017.

[23] V. M. Barthelmes, C. Becchio, and S. P. Corgnati, "Occupant behavior lifestyles in a residential nearly zero energy building: Effect on energy use and thermal comfort", Sci. Technol. Built Environ., vol. 22, no. 7, pp. 960-975, 2016.

[24] K. Sun, T. Hong, and J. Kim, "A simulation framework for quantifying the influence of occupant behaviour on savings of energy efficiency measures", IBPSA Build. Simul. 2017, (2017).

[25] S. Carlucci, F. Causone, L. Pagliano, and M. Pietrobon, "Zero-Energy Living Lab," in Smart Energy Control Systems for Sustainable Buildings, 1st ed., J. Littlewood, C. Spataru, R. J. Howlett, and L. C. Jain, Eds. Springer International Publishing, (2017), p. 67.

[26] F. Causone, S. Carlucci, L. Pagliano, and M. Pietrobon, "A zero energy concept building for the Mediterranean climate," Energy Procedia, vol. 62, no. December, pp. 280-288, (2014).

[27] F. Causone, M. Pietrobon, L. Pagliano, and S. Erba, "A high performance home in the Mediterranean climate: From the design principle to actual measurements," Energy Procedia, vol. 140, pp. 67-79, (2017).

[28] P. Hoes, J. L. M. Hensen, M. G. L. C. Loomans, B. de Vries, and D. Bourgeois, "User behavior in whole building simulation," Energy Build., vol. 41, no. 3, pp. 295-302, (2009).

[29] A. Alfakara and Ben Corxford, "Towards Better Buildings Performance Estimations? A Framework for Integrating Dynamic Occupant Behaviour in Dynamic Buildings Simulation Tools," IBPSA Build. Simul. 2017, pp. 299-308, (2017).

[30] F. Causone, S. Carlucci, M. Ferrando, A. Marchenko, S. Erba, "A data-driven procedure to model occupancy and occupant-related electric load profiles in residential buildings for energy simulation," Energy Build.(under review).

[31] S. Erba, F. Causone, and R. Armani, "The effect of weather datasets on building energy simulation outputs," Energy Procedia, vol. 134, pp. 545-554, (2017).

[32] "ISO 15927-4: 2005. Hygrothermal performance of buildings - Calculation and presentation of climatic data - Part 4: Hourly data for assessing the annual energy use for heating and cooling." . 